\title{
An enhanced chemo-enzymatic method for loading substrates onto carrier protein domains
}

\begin{tabular}{|c|c|}
\hline Journal: & Biochemistry and Cell Biology \\
\hline Manuscript ID & bcb-2017-0275.R1 \\
\hline Manuscript Type: & Article \\
\hline Date Submitted by the Author: & 23-Nov-2017 \\
\hline Complete List of Authors: & $\begin{array}{l}\text { Kittilä, Tiia; Max-Planck-Institut fur medizinische Forschung, Biomolecular } \\
\text { Mechanisms } \\
\text { Cryle, Max J.; Monash University School of Biomedical Sciences, } \\
\text { Biochemistry and Molecular Biology; Max-Planck-Institut fur medizinische } \\
\text { Forschung, Biomolecular Mechanisms }\end{array}$ \\
\hline $\begin{array}{r}\text { Is the invited manuscript for } \\
\text { consideration in a Special } \\
\text { Issue? : }\end{array}$ & N/A \\
\hline Keyword: & $\begin{array}{l}\text { non-ribosomal peptide synthetase, post-translational modification, carrier } \\
\text { protein, phosphopantetheinyl transferase, coenzyme A }\end{array}$ \\
\hline
\end{tabular}




\section{An enhanced chemo-enzymatic method for loading substrates onto carrier}

2 protein domains

3

4 Tiia Kittilä ${ }^{1}$ and Max J. Cryle ${ }^{1,2,3 *}$

5 1. Department of Biomolecular Mechanisms, Max Planck Institute for Medical Research, Jahnstrasse

629,69120 Heidelberg, Germany.

7 2. The Monash Biomedicine Discovery Institute, Department of Biochemistry and Molecular Biology,

8 Monash University, Clayton, Victoria 3800, Australia

9 3. EMBL Australia, Monash University, Clayton, Victoria 3800, Australia.

10 * Address correspondence to: A/Prof Dr. Max Cryle (max.cryle@monash.edu) 


\section{Abstract}

12 Non-ribosomal peptide synthetase (NRPS) machineries produce many medically relevant peptides that cannot be easily accessed by chemical synthesis. Thus, understanding NRPS mechanism is of crucial

14 importance to allow efficient redesign of these machineries in order to produce new compounds.

15 During NRPS-mediated synthesis, substrates are covalently attached to PCPs, and studies of NRPSs 16 are impeded by difficulties in producing PCPs loaded with substrates. Different approaches to load 17 substrates on to PCP domains have been described, but all suffer from difficulties in either the complexity of chemical synthesis or low enzymatic efficiency. Here, we describe an enhanced chemoenzymatic loading method that combines two approaches into a single, highly efficient one-pot loading reaction. First, D-pantetheine and ATP are converted into dephospho-coenzyme A via the actions of two enzymes from coenzyme A (CoA) biosynthesis. Next, phosphoadenylates are dephosphorylated using alkaline phosphatase to allow linker attachment to PCP domain by Sfp mutant R4-4, which is inhibited by phosphoadenylates. This route does not depend on activity of the commonly problematic dephospho-CoA kinase, and therefore offers an improved method for substrate loading onto PCP domains.

Keywords: carrier protein; post-translational modification; non-ribosomal peptide synthetase; phosphopantetheinyl transferase; coenzyme A. 


\section{Introduction}

Non-ribosomal peptide synthetases (NRPSs) produce a wide variety of bioactive molecules, often with complex chemical structures. (Al Toma et al. 2015; Süssmuth and Mainz 2017) Due to this complexity, many such compounds of medicinal interest are still produced through fermentation, which makes understanding NRPS function highly important for future efforts in compound reengineering. NRPS machineries typically utilize a modular architecture of repeating domains to synthesise their peptide products, with the core domains for peptide synthesis being adenylation (A) domains, condensation (C) domains and peptidyl carrier protein (PCP) domains (Figure 1) (Süssmuth and Mainz 2017). A domains select and activate amino acids in an ATP-dependant process and load them onto the phosphopantetheine (PPE) arm of a neighbouring PCP domain, where the amino acid remains tethered as a thioester (Kittilä et al. 2016a). This PCP-bound aminoacyl thioester is then accepted by a C domain, where an upstream PCP-bound amino acid or peptide is condensed to form a new peptide bond with concomitant transfer of the upstream molecule onto the downstream aminoacyl-PCP. By reproducing these catalytic steps, and the introduction of additional tailoring domains, multiple modules can in turn generate peptides whose length is governed by the number of modules within the NRPS (Hur et al. 2012; Payne et al. 2017). Once the peptide has been fully synthesised, a thioesterase (TE)-domain typically cleaves the peptide from the NRPS machinery (Horsman et al. 2016).

Given the significance of the compounds produced by NRPS systems, these assembly lines are important targets for structural and biochemical characterisation (Süssmuth and Mainz 2017). Studying NRPS systems is challenging however due to the complexity of NRPS machineries and the requirement for intermediates to be covalently loaded onto PCP domains before they are recognized as substrates by any catalytic domains (Kittilä et al. 2016a). A domains can be used to load substrates onto PCP domains, but unfortunately A domains can be very selective for their substrates and therefore it is not possible to load a wide range of compounds via this route (Ehmann et al. 2000a; Henderson et al. 2014; Mitchell et al. 2012; Villiers and Hollfelder 2009). In some cases, substrates bound to a small molecule mimic of the PPE-linker (N-acetylcystamine thioesters, SNACs) are 
accepted (Ehmann et al. 2000b; Luo et al. 2002; Roche and Walsh 2003), but this approach lacks general utility as it removes crucial protein-protein interactions and not all NRPS systems accept SNAC-bound substrates (Figure 2). Thus, one of the biggest breakthroughs in NRPS characterization has been the identification of a promiscuous phosphopantetheinyl transferase (PPTase) that can load PCP domains with substrates that are coupled to coenzyme A (CoA): the enzyme Sfp from Bacillus subtilis (Beld et al. 2014; Belshaw et al. 1999; Lambalot et al. 1996; Quadri et al. 1998). This enzyme can load unnatural amino acids and peptides onto PCP domains in vitro, which has enabled detailed characterization of the enzymatic steps during NRPS catalysis. As the Sfp enzyme is promiscuous towards the compounds coupled to $\mathrm{CoA}$, this route has also been used for protein crosslinking, which has been valuable in crystallographic studies (Haslinger et al. 2014; Liu et al. 2011) as well as for protein labelling (La Clair et al. 2004; Shute et al. 2005; Yin et al. 2006).

The major limitation of this PCP loading strategy is the fact that the essential handle for Sfp function $\mathrm{CoA}$ - has limited solubility in solvents appropriate for chemical synthesis, which in turn makes the synthesis of CoA linked substrates challenging - especially when the substrates are hydrophobic in nature. In addition, CoA coupled substrates are not suitable for in vivo studies due to poor membrane permeability. Thus, modified approaches to overcome these limitations have been developed. A less commonly used approach is to use a mutant of the Sfp enzyme to allow substrate loading beyond CoA coupled compounds. The R4-4 Sfp mutant developed by the Yin group was an important development in the field, as it allows any substrate-linker combinations that are coupled to adenosine 5'diphosphate (ADP) to be loaded onto PCP domains (Figure 2) (Zou and Yin 2009). The advantage of this approach is that ADP coupling removes any restrictions on the linker region between the substrate and PCP domain. However, a more versatile route for loading carrier proteins is a chemo-enzymatic route where substrates/probes are synthesized as D-pantetheine derivatives (Figure 2). These can be converted into CoA derivatives by the use of three promiscuous enzymes from the CoA biosynthesis pathway: pantothenate kinase (PanK or CoaA), phosphopantetheine adenylyltransferase (PPAT or CoaD) and dephospho-CoA kinase (DPCK or CoaE) (Nazi et al. 2004). The derivatives thus formed can then be loaded to PCP domains using Sfp. This route allows a wide range of compounds to be 
loaded on to carrier proteins as demonstrated both in vivo (Clarke et al. 2005; Meier et al. 2006) and in vitro (Hur et al. 2009; Meier et al. 2006; Reimer et al. 2016; van Wyk and Strauss 2007).

Although this enzymatic route to CoA-bound substrates is highly functional, several groups have reported problems with the DPCK enzyme, which may contribute to low functionality of the loading cascade (Francois et al. 2006; Rootman et al. 2010; Strauss et al. 2010). To eliminate this problem, we sought to combine the chemo-enzymatic route to CoA analogues together with the use of the R4-4 mutant of Sfp, as this would eliminate the need for DPCK by virtue of the ability of the Sfp R4-4 mutant to load PCP domains with dephospho-CoA coupled substrates (Figure 2). We have explored this strategy and in doing so have been able to establish a simplified loading route for PCP domains that is fast, simple and removes the problematic DPCK enzyme from the PCP loading process.

\section{Materials and methods}

Cloning: The gene encoding ppat from E.coli was obtained as a synthetic gene (ThermoFisher, Geneart $^{\circledR}$ ) and excised from the pEX-K plasmid using NdeI and HindIII restriction enzymes (New England Biolabs). The gene encoding panK was amplified from E. coli strain DH10 $\beta$ using whole cell PCR including primers GGGAATTCCATATGACCGCCAGAAACATGCTTATGAG (forward, NdeI site underlined) and GCGGTAGAAGAGGTCAGACTACGCAAATAAAAGCTTGGAT (reverse, HindIII site underlined) and GoTaq ${ }^{\circledR}$ Green Premix (Promega). Both genes were then subcloned into pET-28(a) vector (Novagen), with inserts and vector cut using NdeI and HindIII-HF restriction enzymes, ligated with T4 ligase. A synthetic gene codon optimized for expression in Escherichia coli encoding $P C P 6_{\text {com }}$ from Streptomyces lavendulae (Chiu et al. 2001) was obtained from Eurofins genomics. The $P C P 6_{\text {com }}$ gene was amplified by PCR using Phusion high fidelity polymerase (NEB) and primers TATTACCATGGCAGGCGGTCGTGATCC (forward, NcoI site underlined) and AATAACTCGAGACCAGTCTCGGGCAGGCTTGCTGCTTCTTCGGC (reverse, XhoI site underlined). $P C P 6_{\text {com }}$ was subcloned into a modified pET vector (Bogomolovas et al. 2009) containing a thioredoxin (Trx) solubility tag followed by a TEV cleavage site and a C-terminal His6-tag under the control of a T7 promoter. All plasmids were used to transform BL21.DE3 Gold cells for protein 
expression. Cloning of Trx-PCP $2_{\text {tei }}$ was performed as described previously (Kittila et al. 2017). The plasmid encoding the Sfp mutant R4-4 was provided by the Yin group (Sunbul et al. 2009).

Protein expression and purification: The Sfp mutant R4-4 was prepared following a protocol previously published by the Walsh laboratory (Yin et al. 2006); Trx-PCP $2_{\text {tei }}$ was also prepared as described previously (Kittila et al. 2017). A single colony was used to inoculate 20-100 mL LuriaBertani (LB) medium supplemented with kanamycin $(50 \mathrm{mg} / \mathrm{L})$ and grown over night at $37^{\circ} \mathrm{C} .4 \mathrm{~L}$ of LB-medium was supplemented with kanamycin $(50 \mathrm{mg} / \mathrm{L})$ and inoculated with the overnight culture (1\%). After the $\mathrm{OD}_{600}$ reached $0.5-0.8\left(37^{\circ} \mathrm{C}, 80 \mathrm{rpm}\right)$, protein expression was induced by the addition of $0.1 \mathrm{mM}$ isopropyl $\beta$-D-1-thiogalactopyranoside. Cultures were then allowed to grow overnight $\left(18^{\circ} \mathrm{C}, 80 \mathrm{rpm}\right)$, after which the cells were harvested by centrifugation $\left(5500 \mathrm{~g}, 10 \mathrm{~min}, 4^{\circ} \mathrm{C}\right)$ and the cell pellets resuspended in lysis buffer (50 mM Tris $\cdot \mathrm{HCl} \mathrm{pH}$ 7.4, $50 \mathrm{mM} \mathrm{NaCl}, 10 \mathrm{mM}$ imidazole). Resuspended cells were flash frozen and stored at $-80^{\circ} \mathrm{C}$ prior to purification.

Cells and proteins were kept on ice or in a cold room throughout the purification; purification steps performed using an Äkta system were performed at RT. Prior to cell lysis, protein inhibitor cocktail tablets (Sigmafast ${ }^{\mathrm{TM}}$, EDTA-free, Sigma-Aldrich) were added to the thawed cells. Cells were lysed by four passes through a microfluidizer (Microfluidics) and the lysate cleared by centrifugation (38800 $\mathrm{g}$, $\left.1 \mathrm{~h}, 4^{\circ} \mathrm{C}\right)$. The cleared lysate was incubated with Ni-NTA beads $\left(4 \mathrm{~mL} /\right.$ construct, $1 \mathrm{~h}, 4^{\circ} \mathrm{C}$, MachereyNagel) with gentle shaking. Beads were washed twice with wash buffer $(50 \mathrm{mM}$ Tris $\cdot \mathrm{HCl}, \mathrm{pH} 7.4,300$ $\mathrm{mM} \mathrm{NaCl}, 10 \mathrm{mM}$ imidazole) and the bound protein eluted with elution buffer (50 mM Tris $\cdot \mathrm{HCl}, \mathrm{pH}$ 7.4, $300 \mathrm{mM} \mathrm{NaCl}, 300 \mathrm{mM}$ imidazole); the elution fraction for PPAT was dialyzed against dialysis buffer (50 mM Tris·HCl, pH 8.0, $150 \mathrm{mM} \mathrm{NaCl}$, overnight). PanK and PPAT were further purified by size exclusion chromatography using a Superose 12 column connected to an Äkta PURE system (GE Healthcare Life Sciences, $50 \mathrm{mM}$ Tris $\cdot \mathrm{HCl}, \mathrm{pH}$ 7.4, $150 \mathrm{mM} \mathrm{NaCl}, 2 \mathrm{mM} \mathrm{MgCl} 2$ ). Protein purity was assessed using $15 \%$ SDS-PAGE, with selected fractions combined and concentrated before being aliquoted, flash frozen and stored at $-80^{\circ} \mathrm{C}$. Protein concentration was determined by $\mathrm{A}_{280}$ absorption (Nanodrop $2000 \mathrm{c}, \varepsilon_{(\mathrm{PanK})}=45380 \mathrm{M}^{-1} \mathrm{~cm}^{-1}, \varepsilon_{(\mathrm{PPAT})}=8480 \mathrm{M}^{-1} \mathrm{~cm}^{-1}, \varepsilon_{(\mathrm{Trx}-\mathrm{PCP} 6 \mathrm{com})}=15470 \mathrm{M}^{-1} \mathrm{~cm}^{-1}$ ). The identity of the purified proteins was confirmed by MALDI-TOF MS peptide mass fingerprinting. 
Activity assays: Activity of PanK was determined using an NADH coupled colorimetric ADP assay (see (Beinker et al. 2005)): $1 \mu \mathrm{M}$ PanK was mixed in assay buffer (50 mM Tris, $\mathrm{pH}$ 7.4, $20 \mathrm{mM} \mathrm{KCl}$, $5 \mathrm{mM} \mathrm{MgCl}_{2}, 1 \mathrm{mM}$ EDTA, $2 \mathrm{mM}$ TCEP, $0.1 \mathrm{~g} / \mathrm{L}$ BSA and $0.2 \mathrm{mM} \mathrm{NADH}, \mathrm{V}_{\text {tot }}=500 \mu \mathrm{L}$ ) with $4 \mathrm{U}$ pyruvate kinase/ 6 U lactic dehydrogenase (Pyruvate kinase/ Lactic dehydrogenase from rabbit muscle (P0294), Sigma-Aldrich) and $0.8 \mathrm{mM}$ phosphoenolpyruvate (Sigma-Aldrich). The reaction was allowed to equilibrate after which $0.5 \mathrm{mM}$ D-pantetheine was added. The reaction was initiated by addition of $1 \mathrm{mM}$ ATP, with the decrease in NADH absorption at $340 \mathrm{~nm}$ monitored over time using a Jasco V-650 spectrophotometer (Jasco).

The activity of PPAT was determined using an NADH coupled $\mathrm{PP}_{\mathrm{i}}$ assay (Kittilä et al. 2016b): $2 \mu \mathrm{M}$ PanK, $0.5 \mathrm{mM}$ D-pantetheine, $2 \mathrm{mM}$ ATP and the components for $\mathrm{PP}_{\mathrm{i}}$ detection were mixed in 100 $\mathrm{mM}$ Tris $\cdot \mathrm{HCl}, \mathrm{pH} 7.4,1 \mathrm{mM} \mathrm{MgCl}, 0.1 \mathrm{mM}$ EDTA and incubated for $10 \mathrm{~min}$ at $25^{\circ} \mathrm{C}$ to allow the formation of phosphopantetheine. $2 \mu \mathrm{M}$ PPAT was subsequently added and the decrease in NADH absorption was observed spectroscopically.

Product formation was confirmed by LCMS measurements: briefly, $2.5 \mu \mathrm{M}$ PanK, $0.5 \mathrm{mM}$ reduced Dpantetheine and $2.5 \mathrm{mM}$ ATP were mixed in assay buffer $(50 \mathrm{mM}$ Tris $\cdot \mathrm{HCl}, \mathrm{pH} 7.4,20 \mathrm{mM} \mathrm{KCl}, 10$ $\mathrm{mM} \mathrm{MgCl} 2)$ and incubated for $30 \mathrm{~min}\left(37^{\circ} \mathrm{C}\right)$. A sample was taken and $25 \mu \mathrm{M}$ of PPAT was added with $1 \mathrm{mM}$ ATP to the remaining sample. The reaction was incubated for $30 \mathrm{~min}\left(37^{\circ} \mathrm{C}\right)$ and a further sample was taken. From both samples the proteins were denaturated at $95^{\circ} \mathrm{C}$ and the resultant precipitate removed by centrifugation. The clarified supernatant was then analyzed by LCMS on a Shimadzu 2020 system (column: XBridge BEH300 Prep C18 column, $10 \mu \mathrm{m}, 4.6$ x 250 mm, Waters; gradient: $2 \% \mathrm{AcN}$ for $4 \mathrm{~min}, 2-10 \% \mathrm{AcN}$ in $11 \mathrm{~min}, 10-40 \% \mathrm{AcN}$ in $10 \mathrm{~min}$; flow rate: $1 \mathrm{~mL} / \mathrm{min}$ ) using positive and negative ionization modes. Product formation was then determined using extracted ion chromatograms.

PCP loading (conventional method): $120 \mu \mathrm{M}$ Trx-PCP $6_{\text {com }}, 240 \mu \mathrm{M}$ CoA or dephospho-CoA and 50 nM Sfp mutant R4-4 were mixed in loading buffer (50 mM Tris, $\mathrm{pH} 7.4,15 \mathrm{mM} \mathrm{MgCl}$, 2 mM DTE); the reaction was incubated for $2 \mathrm{~h}$ at $30^{\circ} \mathrm{C}$ and quenched by the addition of $20 \mathrm{mM}$ EDTA. PCP loading efficiency was determined using MALDI-TOF-MS (intact mass determination, Axima 
163

164

Confidence or Performance, Shimadzu). For examining loading inhibition, 5 mM ATP/ADP/AMP, 4 $\mu \mathrm{M}$ PanK or $5 \mu \mathrm{M}$ PPAT were added to the loading reaction.

PCP loading (one-pot loading reaction): $120 \mu \mathrm{M}$ Trx-PCP $6_{\text {com }}$ or Trx-PCP $2_{\text {tei }}, 2.5 \mu \mathrm{M}$ PanK and 240 $\mu \mathrm{M}$ reduced D-pantetheine, panthenol or pantothenic acid were mixed in assay buffer $(25 \mathrm{mM}$ Tris. $\mathrm{HCl}, \mathrm{pH} 7.4,5 \mathrm{mM} \mathrm{MgCl} 2,0.5 \mathrm{mM}$ DTE). The reaction was initiated by the addition of $0.5 \mathrm{mM}$ ATP. After 5-15 min incubation (RT), $20 \mu \mathrm{M}$ PPAT was added and reaction incubated for a further 10-30 min (RT). Next, $0.4 \mathrm{U} / \mu \mathrm{L}$ of alkaline phosphatase (from calf intestine, grade I (Ref 10108146001), Roche) was added and reaction incubated for an additional $10 \mathrm{~min}$ (RT). The linker was then enzymatically loaded onto the relevant PCP domain by the addition of $0.5 \mu \mathrm{M}$ Sfp R4-4 mutant ( $2 \mathrm{~h}, \mathrm{RT})$. The reaction was quenched by addition of $20 \mathrm{mM}$ EDTA and the loading efficiency analyzed by MALDI-TOF-MS (intact mass determination).

Substrate loading onto PCP domain: $100 \mu \mathrm{M}$ Trx-PCP2 $2_{\text {tei }}$ was loaded with $300 \mu \mathrm{M}$ (D)-tyrosine-4hydroxyphenylglycine-pantetheine (for details of the synthesis see Kittilä et al. 2017) as described above, but with the incubation times reduced to protect the thioester bond from hydrolysis (PanK 5 min, PPAT $10 \mathrm{~min}$, CIP $10 \mathrm{~min}, \mathrm{Sfp}$ R4-4 $15 \mathrm{~min}$ ). Loaded Trx-PCP $2_{\text {tei }}$ was washed four times with $50 \mathrm{mM}$ Tris $\cdot \mathrm{HCl}\left(\mathrm{pH}\right.$ 7.4) (Amicon ${ }^{\circledR}$ ultra ultracentrifugal filters, MWCO $10000,0.5 \mathrm{~mL}$, Merck Millipore) to remove excess peptide. Dipeptide was cleaved from Trx-PCP $2_{\text {tei }}$ with excess of methylamine and sample neutralized with formic acid. Precipitate was removed via centrifugation and supernatant analyzed with UPLC-MS (LCMS-8050, Shimadzu) with single ion monitoring (Column: Acquity UPLC Peptide BEH C18, $1.7 \mu \mathrm{M}, 2.1$ x $100 \mathrm{~mm}$, Waters; Gradient: $5 \%$ acetonitrile for 0.5 $\min , 5-20 \%$ acetonitrile in $20 \mathrm{~min}$; flow rate $0.5 \mathrm{~mL} / \mathrm{min}$ ). A reaction without $\operatorname{Trx}-\mathrm{PCP} 2_{\text {tei }}$ (negative control) was handled with the same protocol.

\section{Results and discussion}

In our initial experiments, we tested the activity of the PanK and PPAT enzymes prior to optimizing the PCP loading assay. Both enzymes were expressed in Escherichia coli and purified in a simple twostep procedure to generate high yields of both purified enzymes $(\mathrm{PanK}=0.7 \mathrm{mmol} / \mathrm{L}, \mathrm{PPAT}=3.8$ 
189

190

191

192

193

194

mmol/L). The enzymatic activities of PanK and PPAT were then assessed using spectroscopic NADH coupled assays (Beinker et al. 2005; Kittilä et al. 2016b). Both enzymes were shown to be active under the assay conditions and product formation was confirmed using LCMS (Figure 3), with the phosphorylated pantetheine needed as a substrate for PPAT produced enzymatically from Dpantetheine by PanK.

After ensuring the production of dephospho-CoA from D-pantetheine, the one-pot PCP-loading reaction was explored. As an acceptor protein, a PCP domain of the NRPS machinery from complestatin biosynthesis (Trx-PCP6 $6_{\text {com }}$ module 6, expressed as a thioredoxin fusion protein to improve yield) was utilized (Chiu et al. 2001). The functionality of the loading reaction was determined by measuring intact mass using MALDI-TOF $\left(\Delta_{m / z}=358\right.$ for phosphopantetheine loaded versus the unloaded PCP domain). Surprisingly no loading of the PCP domain was detected in the one-pot loading reaction, although it has been reported that R4-4 mutant of Sfp is able to load the PPE-linker to PCP domains using dephospho-CoA as a substrate (Sunbul et al. 2009),. After reviewing the substrate binding pocket of Sfp (Mofid et al. 2004), it appeared plausible that the mutation to allow the wider substrate selectivity of the R4-4 mutant enzyme abolished its ability to distinguish between CoA and phosphoadenylates. If this were the case, then ATP, ADP and AMP could potentially bind to Sfp, preventing phosphopantetheine loading on the PCP domain. To test potential Sfp inhibition, we assessed how the different components of the one-pot loading reaction (ATP, ADP, AMP PanK, PPAT) affect the conventional loading reaction, where the linker is derived from CoA. The components were added individually to the loading reaction although they are not needed for linker loading from CoA. No PPE-loading was detected in the presence of phosphoadenylates, whilst the addition of PanK or PPAT did not influence the loading reaction (Figure 4). Therefore, the hypothesis of phosphoadenylates inhibiting Sfp mutant R4-4 seemed to be the most likely explanation for the lack of loading from our initial one-pot reaction.

To overcome this unwanted inhibition, we introduced alkaline phosphatase from calf-intestinal (CIP) into the loading reaction. CIP is commonly used to dephosphorylate DNA as it cleaves phosphates from the 5'end of DNA. Addition of CIP to the PCP-loading reaction was therefore expected to 
216 dephosphorylate the problematic phosphoadenylates but not the desired dephospho-CoA product. This 217 strategy proved to be successful and loading of PCP domains could now be achieved (Figure 5). As all 218 of the loading enzymes (PanK, PPAT, Sfp) have been reported to be promiscuous, a wide variety of 219 pantetheine analogs should be able to be loaded onto PCP domains. To test this, the one-pot loading 220 reaction was also tested using D-pantothenic acid and D-panthenol to provide the linker regions for 221 PCP loading. Both compounds were converted to dephospho-CoA analogs and loaded successfully on 222 the PCP domain using our established one-pot loading method (Figure 5).

223 To demonstrate the functionality of this loading strategy towards different PCP domains and that the 224 loading strategy can also be used for substrate loading, loading of a PCP domain derived from the 225 teicoplanin producing NRPS machinery (Trx-PCP $2_{\text {tei }}$, module 2 (Kittila et al. 2017)) was studied. Trx$226 \mathrm{PCP} 2_{\text {tei }}$ was first successfully loaded using the one-pot loading strategy with the linker derived from 227 pantetheine (Figure 6A). Next, we successfully loaded linked substrates - pantetheine dipeptide 228 thioesters - onto the PCP domain using our established method (Figure 6B). Furthermore, we have 229 been able to employ these loaded substrates to study catalytic steps in synthesis of glycopeptide 230 antibiotics (Kittila et al. 2017). 
231 In conclusion, the R4-4 mutant of Sfp enables loading of PCP domains in a one-pot loading reaction

232 after dephosphorylation of phosphoadenylates. The main advantage of this new PCP loading method is 233 that the phosphorylation of dephospho-CoA catalyzed by DPCK is not needed to achieve PCP loading.

234 The reaction catalyzed by DPCK is reversible (Strauss et al. 2010) and removal of the pyrophosphate 235 formed in the step catalyzed by PPAT could well be required for efficient product formation when 236 DPCK is present. In addition, the activity of DPCK has been reported to reduce over time (Rootman et 237 al. 2010) and some groups have reported problems in achieving high activity through protein 238 purification (Francois et al. 2006). Therefore, removing the need for this step is likely to prove 239 advantageous in loading substrates onto PCP domains for future studies on NRPS systems, with the 240 protocol described herein proving to be a simple and robust method to achieve this essential 241 modification of PCP domains.

\section{Acknowledgements}

243 The authors are grateful to G. Stier (BZH-Heidelberg) for the thioredoxin fusion protein vector; to J.

244 Yin (Georgia State University) for the R4-4 Sfp expression plasmid; to Melanie Müller and Marion

245 Gradl (MPIMF-Heidelberg) for mass spectral analysis; to Melanie Schoppet (MPIMF-Heidelberg/

246 Monash University) for dipeptide thioester substrate synthesis; and to Alexa Weinmann and Veronika

247 Ulrich (MPIMF-Heidelberg) for assistance with construct cloning and protein preparation. T.K. is 248 grateful for the support of the Deutsche Akademischer Austausch Dienst (DAAD Graduate School 249 Scholarship Program); M.J.C. is grateful for the support of the Deutsche Forschungsgemeinschaft 250 (Emmy-Noether Program, CR 392/1-1), Monash University and the EMBL Australia program. 


\section{References}

253 Al Toma, R.S., Brieke, C., Cryle, M.J., and Süssmuth, R.D. 2015. Structural aspects of 254 phenylglycines, their biosynthesis and occurrence in peptide natural products. Nat Prod Rep 32, 12072551235.

256 Beinker, P., Schlee, S., Auvula, R., and Reinstein, J. 2005. Biochemical Coupling of the Two 257 Nucleotide Binding Domains of ClpB: covalent linkage is not a prerequisite for chaperon activity 258 Journal of Biological Chemistry 280, 37965-37973.

259 Beld, J., Sonnenschein, E.C., Vickery, C.R., Noel, J.P., and Burkart, M.D. 2014. The 260 phosphopantetheinyl transferases: catalysis of a post-translational modification crucial for life. Natural 261 Product Reports 31, 61-108.

262 Belshaw, P.J., Walsh, C.T., and Stachelhaus, T. 1999. Aminoacyl-CoAs as probes of condensation 263 domain selectivity in nonribosomal peptide synthesis. Science 284, 486-489.

264 Bogomolovas, J., Simon, B., Sattler, M., and Stier, G. 2009. Screening of fusion partners for high 265 yield expression and purification of bioactive viscotoxins. Protein Expression and Purification 64, 1626623.

267 Chiu, H.-T., Hubbard, B.K., Shah, A.N., Eide, J., Fredenburg, R.A., Walsh, C.T., and Khosla, C. 2001. 268 Molecular cloning and sequence analysis of the complestatin biosynthetic gene cluster. Proceedings of 269 the National Academy of Sciences 98, 8548-8553.

270 Clarke, K.M., Mercer, A.C., La Clair, J.J., and Burkart, M.D. 2005. In vivo reporter labeling of 271 proteins via metabolic delivery of coenzyme A analogues. Journal of the American Chemical Society $272 \quad 127,11234-11235$.

273 Ehmann, D.E., Shaw-Reid, C.A., Losey, H.C., and Walsh, C.T. 2000a. The EntF and EntE adenylation 274 domains of Escherichia coli enterobactin synthetase: Sequestration and selectivity in acyl-AMP 275 transfers to thiolation domain cosubstrates. Proceedings of the National Academy of Sciences 97, $276 \quad 2509-2514$.

277 Ehmann, D.E., Trauger, J.W., Stachelhaus, T., and Walsh, C.T. 2000b. Aminoacyl-SNACs as small278 molecule substrates for the condensation domains of nonribosomal peptide synthetases. Chem Biol 7, 279765. 
Francois, J.A., Starks, C.M., Sivanuntakorn, S., Jiang, H., Ransome, A.E., Nam, J.W., Constantine,

C.Z., and Kappock, T.J. 2006. Structure of a NADH-insensitive hexameric citrate synthase that resists acid inactivation. Biochemistry 45, 13487-13499.

Haslinger, K., Brieke, C., Uhlmann, S., Sieverling, L., Süssmuth, R.D., and Cryle, M.J. 2014. The

Structure of a Transient Complex of a Nonribosomal Peptide Synthetase and a Cytochrome P450 Monooxygenase. Angew Chem, Int Ed 53, 8518-8522.

Henderson, J.C., Fage, C.D., Cannon, J.R., Brodbelt, J.S., Keatinge-Clay, A.T., and Trent, M.S. 2014.

Antimicrobial Peptide Resistance of Vibrio cholerae Results from an LPS Modification Pathway Related to Nonribosomal Peptide Synthetases. ACS Chemical Biology 9, 2382-2392.

Horsman, M.E., Hari, T.P.A., and Boddy, C.N. 2016. Polyketide synthase and non-ribosomal peptide synthetase thioesterase selectivity: logic gate or a victim of fate? Natural Product Reports 33, 183-202. Hur, G.H., Meier, J.L., Baskin, J., Codelli, J.A., Bertozzi, C.R., Marahiel, M.A., and Burkart, M.D. 2009. Crosslinking Studies of Protein-Protein Interactions in Nonribosomal Peptide Biosynthesis. Chemistry \& Biology 16, 372-381.

294 Hur, G.H., Vickery, C.R., and Burkart, M.D. 2012. Explorations of catalytic domains in nonribosomal peptide synthetase enzymology. Natural Product Reports 29, 1074-1098.

Kittila, T., Kittel, C., Tailhades, J., Butz, D., Schoppet, M., Buttner, A., Goode, R.J.A., Schittenhelm, R.B., van Pee, K.-H., Sussmuth, R.D., et al. 2017. Halogenation of glycopeptide antibiotics occurs at the amino acid level during non-ribosomal peptide synthesis. Chemical Science 8, 5992-6004.

Kittilä, T., Mollo, A., Charkoudian, L.K., and Cryle, M.J. 2016a. New Structural Data Reveal the Motion of Carrier Proteins in Nonribosomal Peptide Synthesis. Angewandte Chemie International Edition 55, 9834-9840.

Kittilä, T., Schoppet, M., and Cryle, M.J. 2016b. Online Pyrophosphate Assay for Analyzing Adenylation Domains of Nonribosomal Peptide Synthetases. ChemBioChem 17, 576-584. carrier proteins in antibiotic biosynthesis. Chemistry \& Biology 11, 195-201. 
Lambalot, R.H., Gehring, A.M., Flugel, R.S., Zuber, P., LaCelle, M., Marahiel, M.A., Reid, R.,

307 Khosla, C., and Walsh, C.T. 1996. A new enzyme superfamily - the phosphopantetheinyl transferases.

308 Chem Biol 3, 923-936.

309 Liu, Y., Zheng, T., and Bruner, Steven D. 2011. Structural basis for phosphopantetheinyl carrier

310 domain interactions in the terminal module of nonribosomal peptide synthetases. Chemistry \&

311 Biology 18, 1482-1488.

312 Luo, L., Kohli, R.M., Onishi, M., Linne, U., Marahiel, M.A., and Walsh, C.T. 2002. Timing of 313 epimerization and condensation reactions in nonribosomal peptide assembly lines: Kinetic analysis of 314 phenylalanine activating elongation modules of tyrocidine synthetase B. Biochemistry 41, 9184-9196.

315 Meier, J.L., Mercer, A.C., Rivera, H., and Burkart, M.D. 2006. Synthesis and Evaluation of 316 Bioorthogonal Pantetheine Analogues for in Vivo Protein Modification. Journal of the American 317 Chemical Society $128,12174-12184$.

318 Mitchell, C.A., Shi, C., Aldrich, C.C., and Gulick, A.M. 2012. Structure of PA1221, a Nonribosomal 319 Peptide Synthetase Containing Adenylation and Peptidyl Carrier Protein Domains. Biochemistry 51, $320 \quad 3252-3263$.

321 Mofid, M.R., Finking, R., Essen, L.O., and Marahiel, M.A. 2004. Structure-Based Mutational 322 Analysis of the 4'-Phosphopantetheinyl Transferases Sfp from Bacillus subtilis: Carrier Protein 323 Recognition and Reaction Mechanism†, †. Biochemistry 43, 4128-4136.

324 Nazi, I., Koteva, K.P., and Wright, G.D. 2004. One-pot chemoenzymatic preparation of coenzyme A 325 analogues. Anal Biochem 324, 100-105.

326 Payne, J.A.E., Schoppet, M., Hansen, M.H., and Cryle, M.J. 2017. Diversity of nature's assembly lines 327 - recent discoveries in non-ribosomal peptide synthesis. Molecular BioSystems 13, 9-22.

328 Quadri, L.E., Weinreb, P.H., Lei, M., Nakano, M.M., Zuber, P., and Walsh, C.T. 1998. 329 Characterization of Sfp, a Bacillus subtilis phosphopantetheinyl transferase for peptidyl carrier protein 330 domains in peptide synthetases. Biochemistry 37, 1585-1595.

331 Reimer, J.M., Aloise, M.N., Harrison, P.M., and Martin Schmeing, T. 2016. Synthetic cycle of the 332 initiation module of a formylating nonribosomal peptide synthetase. Nature 529, 239-242. 
333

334

335

336

337

338

339

340

341

342

343

344

345

346

347

348

349

350

351

352

353

354

355

356

357

Roche, E.D., and Walsh, C.T. 2003. Dissection of the EntF condensation domain boundary and active site residues in nonribosomal peptide synthesis. Biochemistry 42, 1334-1344.

Rootman, I., de Villiers, M., Brand, L.A., and Strauss, E. 2010. Creating Cellulose-Binding Domain Fusions of the Coenzyme A Biosynthetic Enzymes to Enable Reactor-Based Biotransformations. ChemCatChem 2, 1239-1251.

Shute, T.S., Matsushita, M., Dickerson, T.J., La Clair, J.J., Janda, K.D., and Burkart, M.D. 2005. A site-specific bifunctional protein labeling system for affinity and fluorescent analysis. Bioconjug Chem 16, 1352-1355.

Strauss, E., de Villiers, M., and Rootman, I. 2010. Biocatalytic Production of Coenzyme A Analogues. ChemCatChem 2, 929-937.

Sunbul, M., Marshall, N.J., Zou, Y., Zhang, K., and Yin, J. 2009. Catalytic Turnover-Based Phage Selection for Engineering the Substrate Specificity of Sfp Phosphopantetheinyl Transferase. Journal of Molecular Biology 387, 883-898.

Süssmuth, R.D., and Mainz, A. 2017. Nonribosomal Peptide Synthesis-Principles and Prospects. Angewandte Chemie International Edition 56, 3770-3821.

van Wyk, M., and Strauss, E. 2007. One-pot preparation of coenzyme A analogues via an improved chemo-enzymatic synthesis of pre-CoA thioester synthons. Chemical Communications, 398-400.

Villiers, B.R.M., and Hollfelder, F. 2009. Mapping the Limits of Substrate Specificity of the Adenylation Domain of TycA. ChemBioChem 10, 671-682.

Yin, J., Lin, A.J., Golan, D.E., and Walsh, C.T. 2006. Site-specific protein labeling by Sfp phosphopantetheinyl transferase. Nat Protocols 1, 280-285.

Zou, Y., and Yin, J. 2009. Phosphopantetheinyl transferase catalyzed site-specific protein labeling with ADP conjugated chemical probes. Journal of the American Chemical Society 131, 7548-7549. 


\section{Figure Captions}

359 Figure 1. Non-ribosomal peptide synthesis and examples of important peptide natural products produced by NRPS machineries. NRPS synthesis utilizes a modular architecture that is based upon

361 repeating catalytic domains. Initial amino acid selection and activation is an ATP-dependent process

362 that is performed by adenylation (A) domains. The activated amino acid is then transferred onto a

363 peptidyl carrier protein (PCP) domain, which serve as attachment points for all intermediates during

364 NRPS-mediated biosynthesis. Peptide bond formation is catalyzed by condensation (C) domains,

365 which bind two PCP domains and transfer the upstream substrate onto the amino acid bound on the

366 downstream PCP-domain with concomitant formation of a new peptide bond.

Figure 2. Loading substrates onto PCP domains. Loading substrates onto PCP domains is one of the biggest challenges in NRPS research and therefore several approaches to achieve loaded PCP domains have been established. A domains can be used to load substrates to PCP domains in vitro. First, the linker region needs to be attached in a reaction catalyzed by the phosphopantetheine transferase enzyme Sfp before an A domain can attach the substrate to the free thiol group of the linker. Substrates can also be coupled to coenzyme A chemically and Sfp can be used to load them to PCP domains. A mutant Sfp enzyme (R4-4) loads substrates coupled to ADP, which allows loading of varied linker regions in addition to different substrates. The majority of NRPS domains only accept PCP-bound substrates, but in some cases soluble SNAC-substrates can also be accepted. However, acceptance of such derivatives must be tested for each system separately and their use removes important protein-protein interactions between NRPS domains. Substrates can also be coupled to pantetheine, which can in turn be converted to coenzyme A using three enzymatic steps (chemoenzymatic route). In this work, we explored an improved loading route in which a chemo-enzymatic route is combined with the use of Sfp mutant R4-4. This route is shown with a red arrow, with the

382 steps being bypassed shown in grey. PanK $=$ pantothenate kinase, PPAT $=$ phosphopantetheine adenylyltransferase, $\mathrm{DPCK}=$ dephospho-CoA kinase. 
Figure 3. PanK and PPAT activity. Both enzymes were initially purified to homogeneity $(\mathrm{PanK}=39.3$ $\mathrm{kDa}$, PPAT $=20.3 \mathrm{kDa}$ ), with enzymatic activities analyzed using NADH coupled spectroscopic assays. The PanK reaction was initiated by addition of ATP and subsequent production of ADP was detected. PPAT adenylates phosphopantetheine that is produced by PanK: thus, a PanK reaction was incubated in assay buffer with components to detect $\mathrm{PP}_{\mathrm{i}}$ formation. As $\mathrm{PanK}$ does not produce $\mathrm{PP}_{\mathrm{i}}$, a steady baseline was detected prior to PPAT addition. Product formation was confirmed by LCMS measurement, with traces showing a combined reaction with PanK and PPAT. No remaining starting material (D-pantetheine) was detected.

Figure 4. Inhibition of the one-pot PCP loading reaction. The Sfp mutant R4-4 can load Trx-PCP6 domain using CoA (positive control) or dephospho-CoA - however, the initial one-pot loading reaction tested did not afford successful PCP loading despite the demonstrated functionality of all enzymes. Inhibition of Sfp R4-4 was studied by addition of phosphoadenylates or other enzymes from the loading cascade into a loading reaction utilizing CoA. No loading was observed in the presence of phosphoadenylates, whilst the additional enzymes did not affect loading. Trx-PCP6 $6_{\text {com }}=23750 \mathrm{Da}(-$ Met); PPE-loaded Trx-PCP6 $6_{\text {com }}=24108$ Da (-Met).

Figure 5. One-pot loading reaction including calf intestine alkaline phosphatase (CIP). Addition of CIP to the one-pot loading reaction allowed different linkers to be successfully loaded onto Trx$\mathrm{PCP} 6_{\text {com. }}$. CIP was stored in $3.2 \mathrm{M}$ ammonium sulfate leading to formation of sulfate adducts (sulfate = $96 \mathrm{~g} / \mathrm{mol}$ ); linker loading from CoA by Sfp R4-4 was used as a positive control. Trx-PCP6 $6_{\text {com }}=23750$ Da (-Met), loading with CoA/pantetheine $=24108 \mathrm{Da}$ (-Met), loading with panthotenic acid $=24049$ Da (-Met), loading with panthenol $=24035 \mathrm{Da}(-\mathrm{Met})$. 
409 Figure 6. Loading of Trx-PCP $2_{\text {tei }}$. A) A one-pot loading reaction was used to load Trx-PCP $2_{\text {tei }}$ with 410 linker derived from pantetheine to ensure the functionality of the loading cascade towards different 411 PCP domains. Trx-PCP $2_{\text {tei }}=22475$ Da (-Met), loaded Trx-PCP $2_{\text {tei }}=22833$ Da (-Met). B) Trx-PCP $2_{\text {tei }}$ 412 was loaded with dipeptide coupled to a pantetheine linker using the established one-pot loading 413 cascade. After the loading reaction, the substrate was cleaved from the linker via addition of 414 methylamine and analyzed via UPLC-MS. Two peaks were observed because of dipeptide 415 racemization during synthesis. Hydrolyzed dipeptide ((D)-tyrosine-4-hydroxyphenylglycine, 331 $416 \mathrm{~g} / \mathrm{mol})$ trace shown in grey, methylamine cleaved dipeptide $(344 \mathrm{~g} / \mathrm{mol})$ shown in black. 


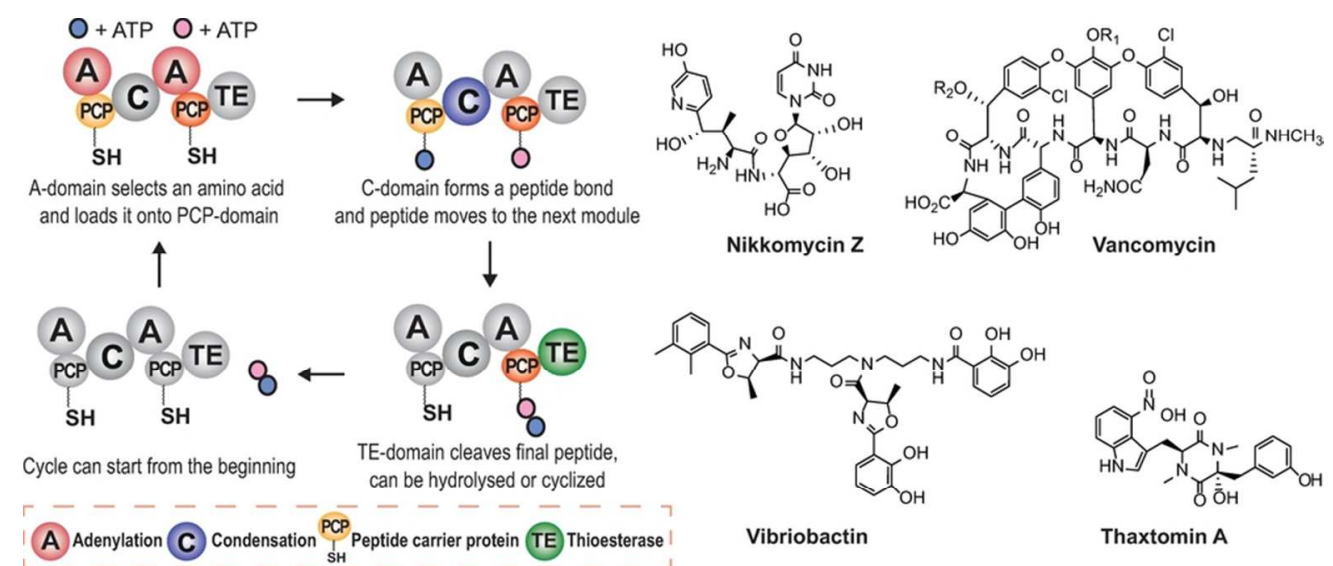

Figure 1. Non-ribosomal peptide synthesis and examples of important peptide natural products produced by NRPS machineries. NRPS synthesis utilizes a modular architecture that is based upon repeating catalytic domains. Initial amino acid selection and activation is an ATP-dependent process that is performed by adenylation (A) domains: the activated amino acid is then transfer onto a peptidyl carrier protein (PCP) domain, which serve as attachment points for all intermediates during NRPS-mediated biosynthesis. Peptide bond formation is catalyzed by condensation (C) domains, which bind two PCP domains and transfer the upstream substrate onto the amino acid bound on the downstream PCP-domain with concomitant formation of a new peptide bond.

$83 \times 37 \mathrm{~mm}(300 \times 300 \mathrm{DPI})$ 


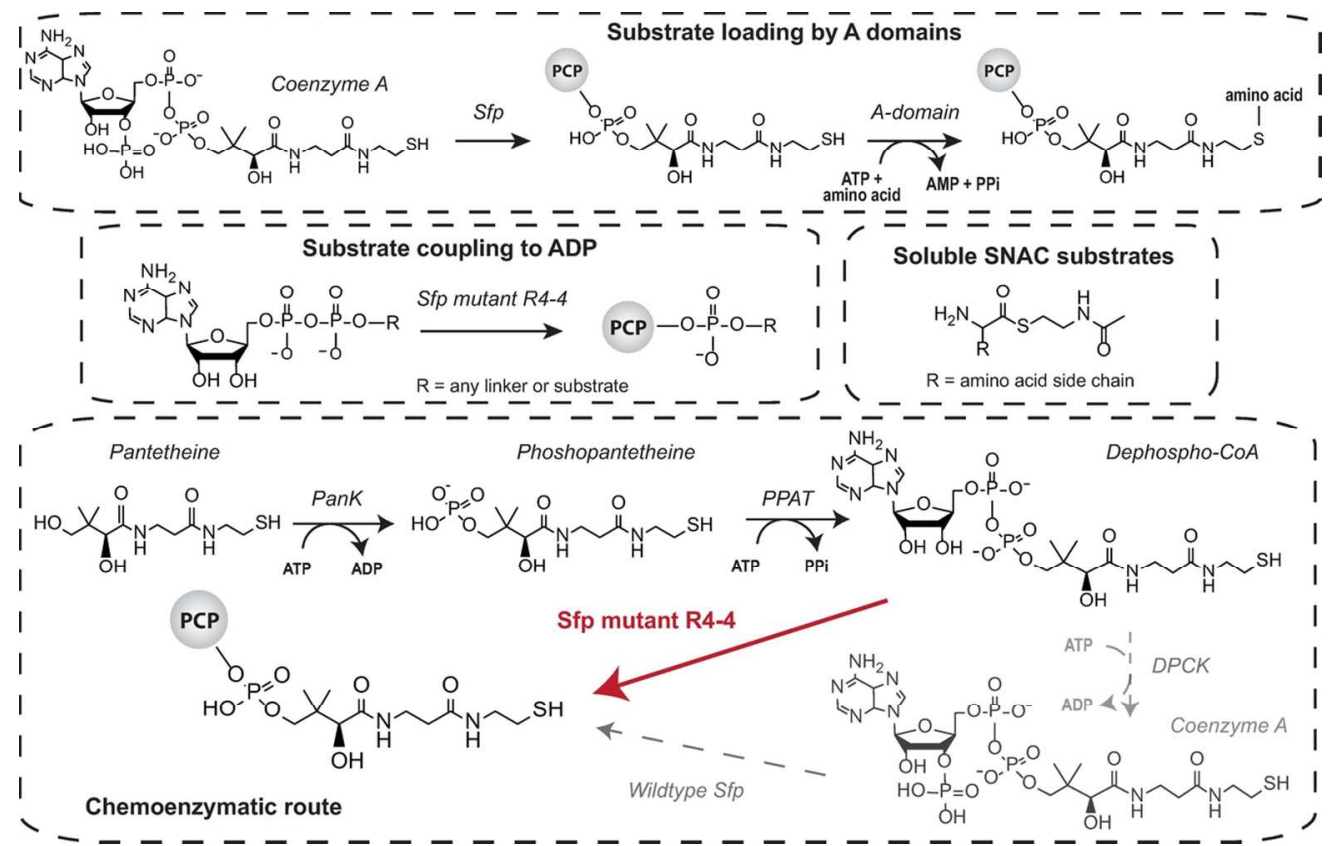

Figure 2. Loading substrates onto PCP domains. Loading substrates onto PCP domains is one of the biggest challenges in NRPS research and therefore several approaches to achieve loaded PCP domains have been established. A domains can be used to load substrates to PCP domains in vitro. First, the linker region needs to be attached in a reaction catalyzed by the phosphopantetheine transferase enzyme Sfp before an A domain can attach the substrate to the free thiol group of the linker. Substrates can also be coupled to coenzyme A chemically and Sfp can be used to load them to PCP domains. A mutant Sfp enzyme (R4-4) loads substrates coupled to ADP, which allows loading of varied linker regions in addition to different substrates. The majority of NRPS domains only accept PCP-bound substrates, but in some cases soluble SNAC-substrates can also be accepted. However, acceptance of such derivatives must be tested for each system separately and their use removes important protein-protein interactions between NRPS domains. Substrates can also be coupled to pantetheine, which can in turn be converted to coenzyme A using three enzymatic steps (chemo-enzymatic route). In this work we explored an improved loading route in which a chemo-enzymatic route is combined with the use of Sfp mutant R4-4. This route is shown with a red arrow, with the steps being bypassed shown in grey. PanK = pantothenate kinase, PPAT = phosphopantetheine adenylyltransferase, DPCK = dephospho-CoA kinase.

$112 \times 72 \mathrm{~mm}(300 \times 300 \mathrm{DPI})$ 


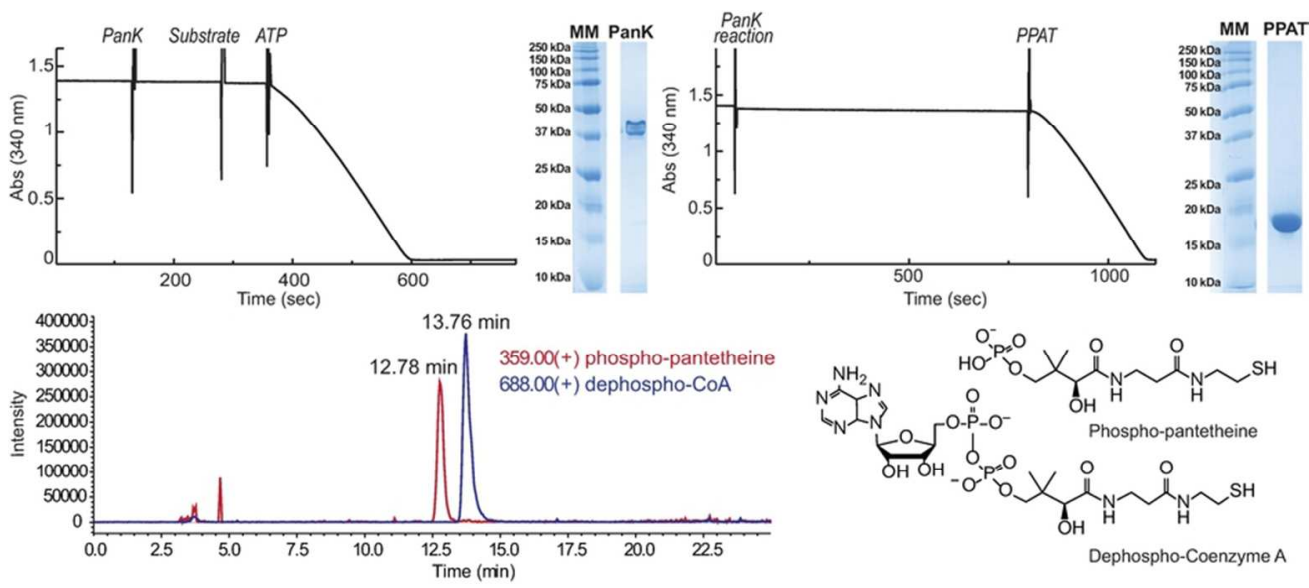

Figure 3. PanK and PPAT activity: both enzymes were initially purified to homogeneity (PanK $=39.3 \mathrm{kDa}$, PPAT $=20.3 \mathrm{kDa}$ ), with enzymatic activities analyzed using NADH coupled spectroscopic assays. The PanK reaction was initiated by addition of ATP and subsequent production of ADP was detected. PPAT adenylates phosphopantetheine that is produced by PanK: thus, a PanK reaction was incubated in assay buffer with components to detect PPi formation. As PanK does not produce PPi, a steady baseline was detected prior to PPAT addition. Product formation was confirmed by LCMS measurement, with traces showing a combined reaction with PanK and PPAT. No remaining starting material (d-pantetheine) was detected.

$79 \times 35 \mathrm{~mm}(300 \times 300$ DPI $)$ 

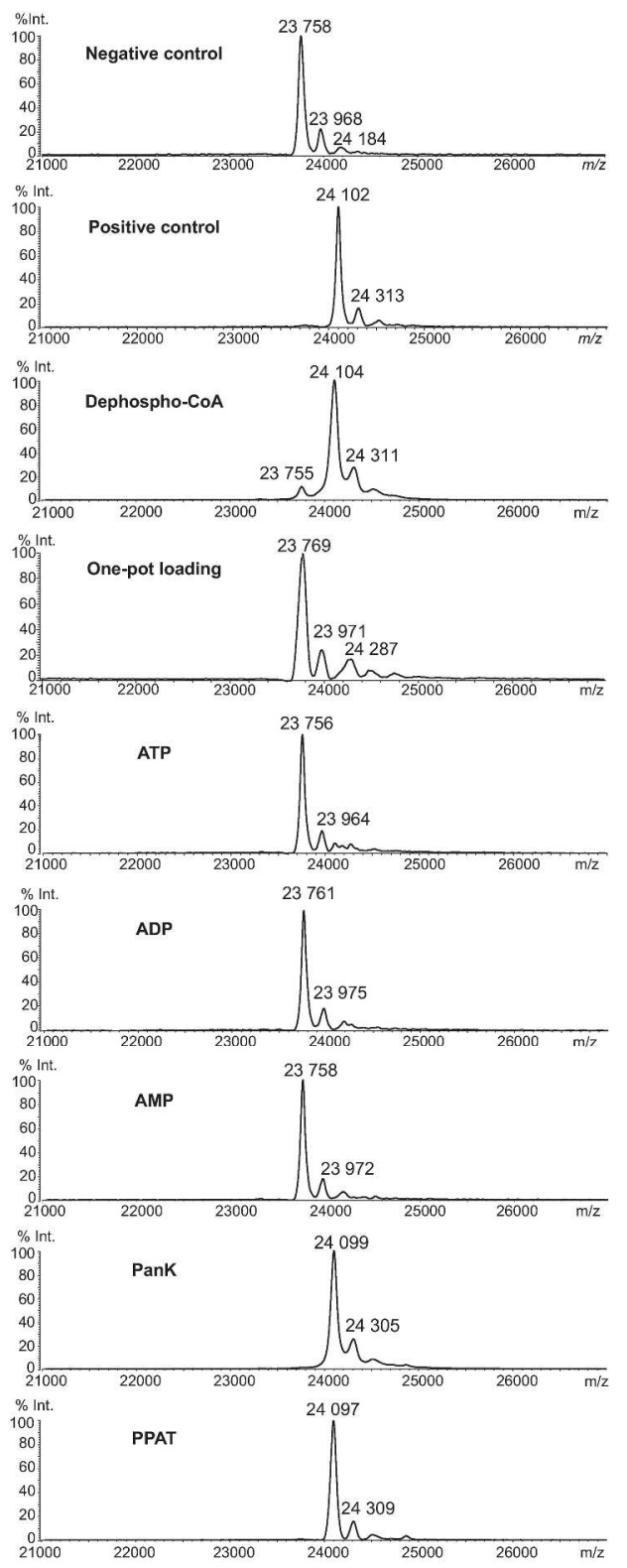

Figure 4. Inhibition of the one-pot PCP loading reaction. The Sfp mutant R4-4 can load Trx-PCP6 com $_{\text {domain }}$ using CoA (positive control) or dephospho-CoA - however, the initial one-pot loading reaction tested did not afford successful PCP loading despite the demonstrated functionality of all enzymes. Inhibition of Sfp R4-4 was studied by addition of phosphoadenylates or other enzymes from the loading cascade into a loading reaction utilizing CoA. No loading was observed in the presence of phosphoadenylates, whilst the additional enzymes did not affect loading. Trx-PCP6 $6_{\text {com }}=23750$ Da (-Met); PPE-loaded Trx-PCP6 $6_{\text {com }}=24108$ Da (Met).

$217 \times 561 \mathrm{~mm}(300 \times 300 \mathrm{DPI})$ 

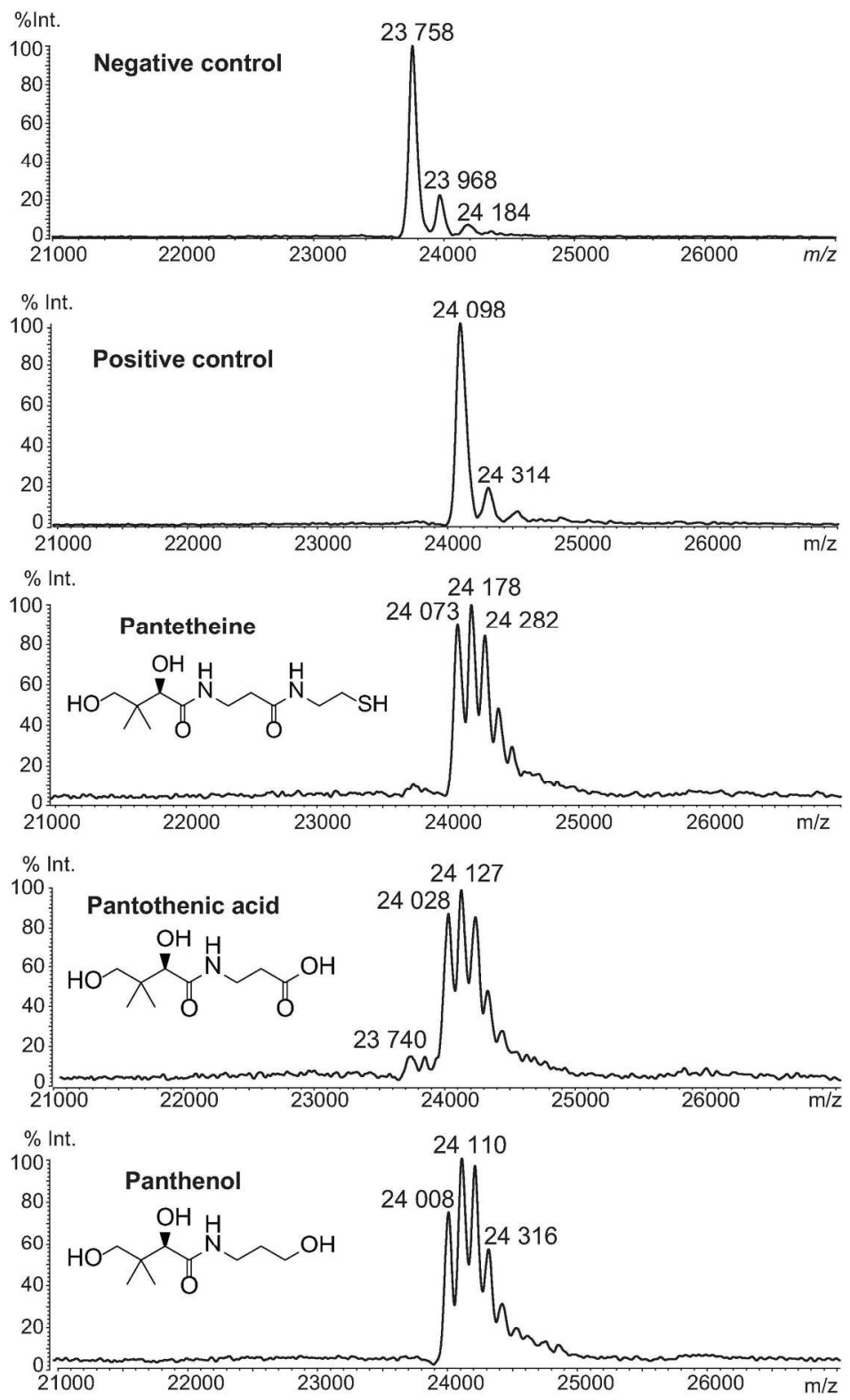

Figure 5. One-pot loading reaction including calf intestine alkaline phosphatase (CIP). Addition of CIP to the one-pot loading reaction allowed different linkers to be successfully loaded onto Trx-PCP6 $6_{\text {com. }}$ CIP was stored in $3.2 \mathrm{M}$ ammonium sulfate leading to formation of sulfate adducts (sulfate $=96 \mathrm{~g} / \mathrm{mol}$ ); linker loading from CoA by Sfp R4-4 was used as a positive control. Trx-PCP6 $6_{\text {com }}=23750$ Da (-Met), loading with $\mathrm{CoA} /$ pantetheine $=24108 \mathrm{Da}$ (-Met), loading with panthotenic acid = $24049 \mathrm{Da}$ (-Met), loading with panthenol $=24035 \mathrm{Da}(-$ Met $)$.

$142 \times 236 \mathrm{~mm}(300 \times 300 \mathrm{DPI})$ 
A)
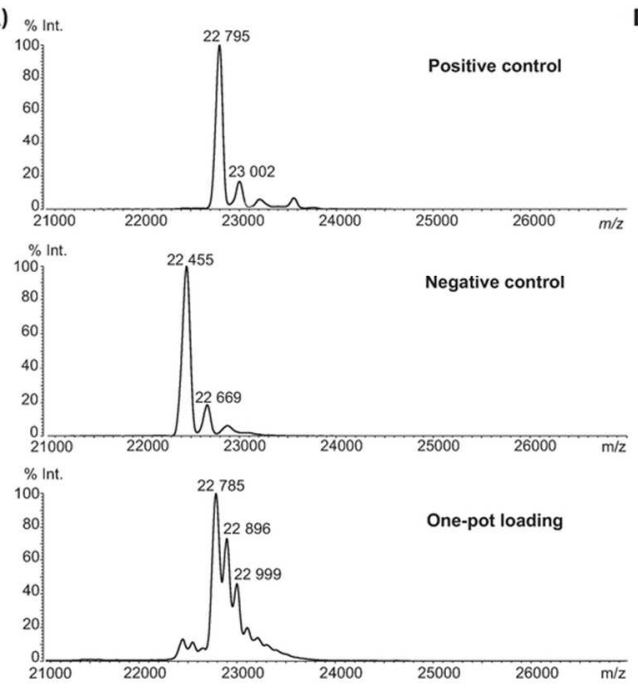

B)
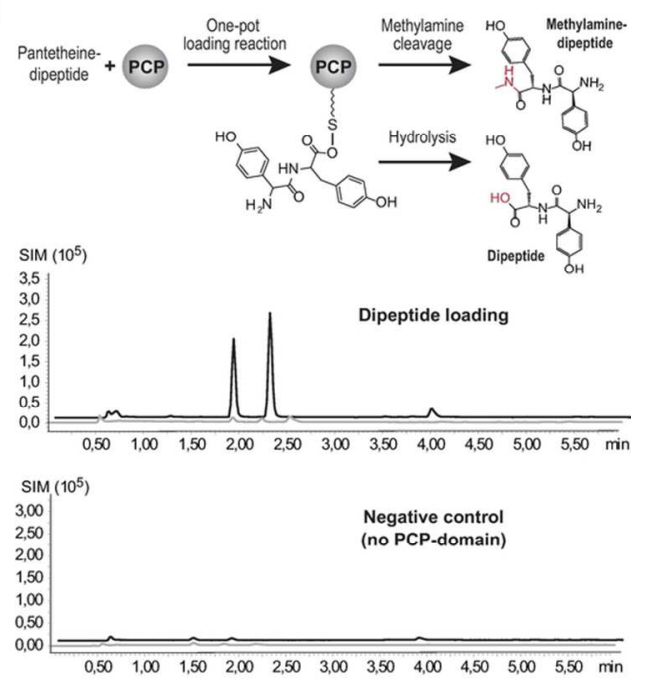

Figure 6. Loading of Trx-PCP2 $2_{\text {tei. }}$ A) A one-pot loading reaction was used to load Trx-PCP2 $2_{\text {tei }}$ with linker derived from pantetheine to ensure the functionality of the loading cascade towards different PCP domains. Trx-PCP2tei = 22475 Da (-Met), loaded Trx-PCP2 $2_{\text {tei }}=22833$ Da (-Met). B) Trx-PCP2 $2_{\text {tei }}$ was loaded with dipeptide coupled to a pantetheine linker using the established one-pot loading cascade. After the loading reaction, the substrate was cleaved from the linker via addition of methylamine and analyzed via UPLC-MS. Two peaks were observed because of dipeptide racemization during synthesis. Hydrolyzed dipeptide ((D)tyrosine-4-hydroxyphenylglycine, $331 \mathrm{~g} / \mathrm{mol}$ ) trace shown in grey, methylamine cleaved dipeptide (344 $\mathrm{g} / \mathrm{mol}$ ) shown in black.

$93 \times 49 \mathrm{~mm}(300 \times 300 \mathrm{DPI})$ 